\title{
On Application of Translation Workshop in Translation Teaching for English Majors
}

\author{
Wang Zhen \\ School of Foreign Languages \\ Jiangxi Science \& Technology Normal University \\ Nanchang, China
}

\author{
He Jianbo \\ School of Tourism \\ Jiangxi Science \& Technology Normal University \\ Nanchang, China
}

\begin{abstract}
With the deepening of China's international development, the demand for translation talents is increasing and the requirements are constantly improving. Therefore, it is particularly important to cultivate translation practice ability of English majors. In the translation teaching of English majors in colleges and universities, the "translation workshop" teaching mode is gradually emerging. This paper starts with the origin and development of translation workshops at home and abroad, and analyzes the feasibility and specific methods of the application of translation workshops in translation teaching for English majors, so as to make a beneficial exploration for translation teaching and training of applied English translation talents.
\end{abstract}

Keywords-translation workshop; english major; teaching mode; translation talents

\section{INTRODUCTION}

In the context of economic globalization and social informationization, the demand for translation talents is increasing with internationalization of China's rising, it is particularly important to carry out courses of translation in translation major students, but the translation teaching for English majors is not ideal, there is a big drawback in the application of traditional translation teaching mode. For example, it emphasizes the teaching of translation theories and ignores the process of translation [1-3]. The evaluation mechanism is single and does not pay attention to the cultivation of students' critical thinking ability; Teachers lack practical experience and other problems. Traditional translation teaching class is closed, the teaching way is usually conducted by the teacher first interpretation of the translation theory and translation skills, training for students, the teacher guide through the contrast analysis of the teaching materials in parallel text, books often contain the same subject matter and form is rarely provide text application class style, each style is given one to two samples and the reference translations, enclosed some stylistic features and translation principles. In addition, traditional translation teaching emphasizes the teaching of basic knowledge and skills of translation. Most of the translated texts and translations have nothing to do with the society and market, and teachers become the only readers and evaluators. These practices are virtual, disconnected from the market, closed rather than open.

Nowadays, China's translation industry is also faced with

Sponsored by:(1) "On Application of Translation Workshop in English Translation Teaching in Colleges and Universities" (Teaching Reform Research Projects of Institutions of Higher Learning in Jiangxi Province, No. JXJG-1510-5). (2)"On Application of Translation Workshop Mode in Translation Teaching for English Majors in Colleges and Universities" (Teaching Reform Research Projects of Jiangxi Science \& Technology Normal University, No. JGZD-14-17-5)

many problems, such as: the translation market is not standard, translation companies are continuing to produce those not in line with the authentic English expressions of translation, we "carefully" trained English major students are still on paper, after graduation with many certificates, but cannot be competent for practical translation work. In China's translation market, the digestibility of translation companies only accounts for about $10 \%$ of the total demand, among which non-literary or practical texts account for $95 \%$ of the total translation [4-7]. This gap means that whether we are in the master's or undergraduate stage of English, the focus is still to train technical application-oriented talents. But in our education system, the status of translation teaching is attached to foreign language teaching, translation is not really as an independent discipline, translation of the training is not a career-oriented. Many educators stubbornly believe that as long as having good language skills and the ability to express can of course be in line with market demand translation talents ignoring the differences between Chinese and western cultural differences and thinking logic.

\section{INTRODUCTION OF TEACHING MODEL OF TRANSLATION WORKSHOP}

Workshop, also known as project study workshop in English. Firstly, it mainly refers to a project-based research learning method, which has gradually evolved into a practical teaching model. The educational concept of "workshop" is to pay equal attention to technology and art, and the learning process is like "factory apprenticeship", and the student's identity is "apprentice". Due to the specific site required for practice, students' daily practice space -- workshop gradually becomes the core of practice. So the practice mode formed by this is also known as "workshop teaching".

Translation Workshop is a practical research on the mutual translation of source language and target language. It breaks the traditional teaching mode of theory before practice and is advocated to be used in the translation teaching of English majors to cultivate students' ability of practical translation and meet the demand of market. In the application of this teaching model, study groups participate in translation activities, brainstorm ideas and discuss translation tasks. It can provide students with a more relaxed and free learning environment when applied to translation teaching of college English majors. Translation teaching for English majors based on translation 
workshops is a student-oriented teaching model. Students will get more opportunities for practical application and are no longer confined to the theoretical framework. They can fully divergent their thinking, which is conducive to improving their translation ability and achieving ideal translation effects.

The "Translation workshop" is learner-centered and process-oriented, through practical practice to improve the learners' ability of identifying translation problems and appropriately apply translation strategies to solve the problems, improve learners engaged in independence or the ability of cooperative translation projects or tasks, grasp applicability principle in the translation process, translation expertise and experience, and finally learn knowledge and skills of translation, grasp the essence of translation and grasp the professional spirit of translation. In translation teaching, pay more attention to real translation projects as the carrier, focus on the various steps in the process of translation, emphasis on language knowledge and professional knowledge accumulation and renewal, pay attention to the authenticity of the selected translation materials [8]. Paying attention to the translators' professional skills, interpersonal skills, ability of translation, cooperation spirit, cooperation ability, the cultivation of the responsibility consciousness and so on, for learners' success in the future to lay the foundation on the road to professional translation.

\section{A. The Concept of Translation Workshop}

Translation workshop is similar to commercial translation centre, where two or more translators come together to carry out translation activities. Taking translation workshop to teach can organize the whole class to do translation activities in groups. The best way to realize translation teaching is to integrate the face-to-face discussions in the form of workshops with the network-based interactive teaching mode, which achieves the "combination of virtuality and reality".

\section{B. The Characteristics of Translation Workshop}

The biggest characteristics of the learning model in a workshop way is to advocate practice as the core and to study theory in accordance with the requirements of practical, not to take theory as the core and to assist practical according to the requirements of theoretical study. It is not only the supplement of theory study in the translation teaching for English majors, but it can be said that it has become the main learning method.

In the specific operation process, there are the following characteristics:

First, project-oriented. We let students to learn in practice and experience practice in learning through reforming traditional teaching models, selecting the most practical and targeted modules and integrating the basic knowledge and skills of translation into the module.

Second, focus on practice and highlight practice. The core of workshop teaching model is practice. The guiding process that faulty advisers and their assistants aim at specific project is the main way for students to learn. Therefore, students can strive to find the practical solutions to solve problems in the process of studying.

\section{Diversified Assessment Based on Project Inspection}

The evaluation of the learning effect of the students is not only the inspection of the theory, the more important is applying their knowledge by a practical process based on theory and the means of a real whole or decomposing project to test the effect of students' response to engineering practice comprehensively.

\section{Varies of Learning Ways Co-exist and Emphasize Self- study}

The process of practical is the process of learning and researching comprehensively, and the process of multipleperson or groups cooperation. In this process, all kinds of learning methods may lie in, such as the guidance of faulty advisers, the experience of senior students, the communication of the students at the same time and self-study, which helps students obtain knowledge from different channels.

\section{THE APPLICATION EFFECT OF TEACHING MODEL BASED ON TRANSLATION WORKSHOP.}

\section{A. Arouse the Enthusiasm of Students Fully.}

The translation teaching for English majors based on translation workshop have a more active atmosphere, which can better attract students' interest and fully arouse their enthusiasm to take participate in English translation. In the teaching model, it realizes that the role of teachers and students is changed. And the class begins to be lead by students, however, teachers mainly play a role of guidance and direction, which enhances the participation of students in classroom [9-10]. During the process of taking participate in English translation and discussion, students be able to give full play to their thinking ability, recall what they have learned and solve translation problems to improve the sense of achievement of students, generating motivation to continue learning and research. In the translation workshop model, students no longer accept knowledge passively, but have a more relaxing and free learning environment and can participate in English practice independently to exercise their application ability, which has a positive assistance in improving students' translation level.

\section{B. Improve the Effectiveness of Translation Teaching.}

For students major in English in college, translation ability is an important skill in their future employment. Therefore, translation teaching cannot be limited to theory, but ought to highlight the combination of theory and practice in order to help students improve their translation ability better. And the application of translation workshop in teaching further improve the effectiveness of translation teaching. In the process of participating, students be able to obtain more translation materials involving science and technology, medical treatment, business and other practical applications. This kind of translation materials has the feature of profession, which tests the students' translation ability especially and exercises students fully. And students can learn more translation skills from it to work out problems in the translation study. It has great signification on students' growth and development in the future. 


\section{Increase the Cooperation and Interaction in the Classroom}

In the teaching model based on translation workshop, students focus on common translation tasks and put hands together, which not only solves the translation problems, but also improves the quality of translation works in the process of communication and cooperation. At the same time, students can find errors in translation in time, correct them in time, sum up experience from it in time and deepen their impression. In addition, the cooperation and interaction in the classroom is conducive to create a more harmonious learning atmosphere.

\section{THE ENLIGHTENMENT OF TRANSLATION WORKSHOP TEACHING ON TRAINING OF APPLIED PROFESSIONAL TRANSLATION TALENTS}

According to the market research, the translation market's demand for translation talents mainly consists of three parts: First, basic bilingualism and extra linguistic ability; second, core translation knowledge and strategic ability; third, translation skills and project management ability. At present, colleges and universities mainly focus on the teaching of the first and second parts, while the last part is relatively limited, mainly due to its strong practicality and limitations. As a new model of translation teaching, translation workshop is of farreaching significance to the cultivation of applied professional translation talents.

- "Translation workshop" teaching mode realize the stimulation of the translation market cooperative mode , provides a good platform for the practice of English major students. It's teaching goal is to cultivate students' vocational ability, strong practicality and maneuverability. As the principal part of teaching, the students practice in learning, learn in practice.

- In the teaching mode of "translation workshop", highintensity translation training is realized, which enables students to practice their translation skills, find translation rules and skills in a large number of practical translation work, strengthen the application of various translation AIDS, and enhance their ability to find problems and solve problems independently.

- Due to "translation workshop" mode is similar to the "translation center" on the market, in which the students form a project team, so students must play different roles. This also puts forward higher request to the student's division of labor cooperation ability, improves the students' cooperation consciousness, responsibility consciousness. It is also the quality a professional interpreter must have.

- In the teaching mode of "translation workshop", teachers play the role of "guide", that is, guide students to carry out project translation and discussion, and play an auxiliary role. Students independently plan the project operation to enhance their practical experience.

- In the teaching mode of "translation workshop", after the translation is submitted to the client by the project team composed of students, it is necessary to modify and improve the translation according to various opinions of the client, which is conducive to making students understand the norms and requirements of the translation market and enhancing their awareness of finished products and quality.

\section{CONCLUSION}

The application of translation workshop teaching mode in translation teaching of college English majors applies taskoriented and project-driven teaching mode combining work with study to English teaching in a more systematic and real way. The integration of post, job, really realizes the objectives and requirements of undergraduate education talent training, fully arouses the enthusiasm of the students, and improves the actual effect of translation teaching, at the same time, active classroom atmosphere, can make students more involved in the practice, better exercise their translation ability, improve their translation level. In order to achieve more ideal teaching effects, it is also necessary to scientifically position the translation workshop teaching of college English majors, integrate with multiple disciplines and expand the space of translation teaching, which has a positive impact on the training of translation talents.

\section{REFERENCES}

[1] Gentzler, Edwin. Contemporary Translation Theories[M]. London: Rutledge, 1993

[2] Li Changshuan. Theory and Practice of Non-literary translation[M]. Beijing: China Translation \& Publishing Corporation, 2004.

[3] Xiao Hong. Application of translation workshop in translation teaching [J]. Journal of Sichuan Foreign Languages University, 2005 (01) : 139142 .

[4] Zhong Weihe. Undergraduate teaching requirements for translation majors in colleges and universities [J]. Chinese Translators, 2011 (03):20-24.

[5] Ji Hong. Practice of translation workshop in translation teaching [J]. Journal of Bingtuan Education Institute, 2013 (03) : 43-45+51.

[6] Zeng Lixin, Sun Xiaoyun. A preliminary study on the teaching mode of computer-assisted translation workshop [J]. Journal of Gansu Normal Colleges, 2016 (05) : 29-32.

[7] Liu Rui, Yang Nan. Translation workshop model and training of applied translation talents [J]. Journal of Heilongjiang College of Education, 2016 (09) : 115-117.

[8] Huang Shuyi, Feng Junxia, Li Xiaofan. On Construction of Translation Workshop Practice Teaching Mode in Private Higher Learning Institutions [J]. Education Modernization, 2019(42): 191-193+206.

[9] Jia Yan. On Translation Workshop Teaching Mode Based On the Flipped Classroom [J]. Teaching of Forestry Region, 2019(05): 76-77.

[10] Zhu Xuelin. On Aim Design and Realization Routine Translation Workshop Teaching [J]. Heilongjiang Researches on Higher Education, 2015(12): 160-162. 